\title{
¿Communicating Heat-Health Information to the Public: Assessing Municipal Government Extreme Heat Event Website Content
}

\author{
Lisa K. ZotTARelli, ${ }^{\mathrm{a}}$ StARla A. Blake, ${ }^{\mathrm{b}}$ And Michelle T. GARZA ${ }^{\mathrm{b}}$

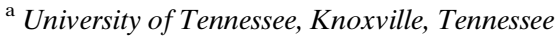 \\ ${ }^{\mathrm{b}}$ University of Texas at San Antonio, San Antonio, Texas
}

(Manuscript received 24 January 2021, in final form 14 May 2021)

\begin{abstract}
Extreme heat events pose a threat to human health. Forecasting and warning strategies have been developed to mitigate heat-health hazards. Yet, studies have found that the public lacks knowledge about their heat-health risks and preventive actions to take to reduce risks. Local governmental websites are an important means to communicate preparedness to the public. The purpose of this study is to examine information provided to the public on municipal government web pages of the 10 most populous U.S. cities. A two-level document and content analyses were conducted. A direct content analysis was conducted using federal government websites and documents to create the Extreme Heat Event Public Response Rubric. The rubric contains two broad categories of populations and actions that are further specified. The rubric was then used to examine local government extreme heat event websites for the 10 most populous cities in the United States. The examination of the local government sites found that information included on the websites failed to identify the breadth of populations at greater risk for adverse heat-health outcomes and omitted some recommended actions designed to prevent adverse heat-health events. Local governments often communicated concrete and simple content to the public but more complex information was not included on their websites.
\end{abstract}

SIGNIFICANCE STATEMENT: Extreme heat is the leading weather-related cause of mortality in the United States annually. Public response to extreme heat events requires that the public understand their risk and know the actions to take to mitigate that risk. The public seeks information from local government websites. Our results found that many local government websites did not provide the information to the public on the array of conditions and factors that put people at a greater risk for an adverse heat-health event, nor did the websites include information on the variety of actions that the public should take in response to an extreme heat event in order to reduce their risks. Addressing the omission of the information on these websites may improve public response to extreme heat events.

KEYWORDS: Emergency preparedness; Emergency response; North America; Vulnerability

\section{Introduction}

An extreme heat event (EHE) refers to hot weather conditions, such as heat waves, high daily temperatures, and high heat indexes, which pose a threat to human health (EPA and CDC 2016). EHEs are a hazard in much of the United States, and forecasts predict increases in the number and intensity of events in all major metropolitan areas (Union of Concerned Scientists 2019). There are established links between mortality and extreme heat events in cities across the United States (Anderson and Bell 2011; Matte et al. 2016; Semenza et al. 1996). Additionally, there is growing evidence of increased morbidity associated with extreme heat events, especially for vulnerable populations (Fuhrmann et al. 2016; Zhang et al. 2015; Zottarelli et al. 2020). Localized forecasting and warning strategies have been developed to inform the public in an effort to mitigate the effects of heat-health hazards (Hawkins et al. 2017). Multiple channels are used to communicate this information to the public including official municipal

\footnotetext{
๑Denotes content that is immediately available upon publication as open access.
}

Corresponding author: Lisa K. Zottarelli, lzottare@utk.edu government emergency preparedness and response websites. Yet, it remains unclear if mitigation strategies communicated to the public on municipal government websites encompass information that the public needs in order to effectively respond to an EHE. Therefore, the goal of this study is to examine extreme heat event preparedness and response information communicated to the public on municipal government web pages.

Preparedness communication is an important component in preparing the public to take protective actions during a hazard event. Research on disaster-related communication has examined information source along with communication channel used to communicate preparedness information to the public, and has included traditional media (e.g., local news station televised broadcast, newspaper articles, and local media radio broadcasts), social media (e.g., Facebook posts, Twitter tweets, Instagram photos), government preparedness websites (e.g., city public health department official websites and Department of Homeland Security's website https://www. ready.gov/), and nongovernmental organization websites (e.g., American Red Cross and United Way). The results of this body of research are mixed and there is a lack of consistency in the operationalization and findings about how the public perceives communication sources as well the preferred channels of communication during disasters (Liu et al. 2016). 
There is evidence that the public uses asynchronous communication channels (including websites) in dynamic events such as hurricanes (DeYoung et al. 2016; Diwanji et al. 2020; Liu et al. 2016).

Websites as tools for preparedness rely on the premise that the audience will engage with the material through selfdirected learning (McDonough et al. 2015). In the United States, people increasingly rely on the internet for health information (Henderson et al. 2016; Wimble 2016) and for information related to disasters and emergency preparedness (Friedman et al. 2008). The public sector, including local governments, invests time, space, and other resources into developing a website presence to provide constituents with a variety of information and services, including information on local hazards and disaster preparedness. The internet is perceived by the public as an appropriate channel for information collection (Reddick and Anthopoulos 2014). An important motivation for providing official government websites is to empower users to access information and to build trust and satisfaction in government (Bannister and Connolly 2011). When given a choice of channel access to government services, people use the online channel (i.e., web pages) for consultation, registration, and transaction interactions (Ebbers et al. 2016).

EHE are complex events that require an understanding of personal vulnerabilities to heat, such as underlying medical conditions or work-related exposure, and require individual actions to mitigate risk, such as staying hydrated or the safe use of electric fans. Multiple channels of communication, including government websites, are necessary to promote public heat-health preparedness, especially in heat-islandprone metropolitan areas (Madrigano et al. 2018). Yet, information provided on websites can be problematic in terms of suitability of content and communication elements (McDonough et al. 2015; Schmalzried et al. 2012). Even people aware of a heat warning can fail to recognize their vulnerability to an extreme heat event (Bassil and Cole 2010). Further, the general public lacks an understanding of actions to take during an EHE to mitigate its risk (Bassil and Cole 2010; Sheridan 2007). Therefore, it is not surprising that municipal heat warnings have not been shown to reduce mortality in most cities studied, and this is attributed to a gap between EHE communication and public behaviors (Sheridan 2007).

Local governments issue heat advisories and warnings to inform the public and protect lives. The heat advisories and warnings are publicized via media channels. As part of the messaging, often the public are directed to seek additional information on local government extreme heat event websites. There is some evidence that when effectively communicated, public health interventions did reduce heat-related mortality during a heat wave in Milwaukee, Wisconsin (Weisskopf et al. 2002). However, if the guidance provided on the official EHE website does not include information necessary for the public to understand their risks as well as the actions to take to mitigate risk, it may result in greater risk exposure for the public.

Despite a growing awareness of the threat of extreme heat events in United States, there are no established standards for content that should be included in EHE preparedness materials, and no published study has examined the preparedness and response content communicated to the public via municipal web pages. Some federal agencies do provide guidance to promote various aspects of heat health. For example, the Centers for Disease Control and Prevention (CDC) has the role of "promoting healthy and safe behaviors, communities, and environment" and seeks to support local efforts to meet this goal (CDC 2019a). The CDC's Climate Ready States and Cities Initiatives seeks to address the lack of state and local level preparedness (CDC 2019b). The CDC, National Oceanic and Atmospheric Administration (NOAA), and a number of partnering agencies have developed the National Integrated Heat Health Information System (NIHHIS) that aims to use science-based information to reduce heat-related morbidity and mortality (NIHHIS 2020). NIHHIS is expanding its work with local governments to support decisionmakers and policy makers. The NOAA/National Weather Service (NWS) mission is to "provide weather, water, and climate data, forecasts and warnings for the protection of life and property and enhancement of the national economy," and it does so for local government authorities to support planning, preparation, mitigation, and response to natural and human-caused events (NWS 2020). In fact, the NWS Heat Index and Heat Health Warning Systems classification is used to inform local government responses to EHEs (Hawkins et al. 2017).

A component of federal responsibility is to support local government efforts to prepare and respond to hazards, including extreme heat. Federal agencies can be sources of information to support local efforts at public preparedness and response. Given tight local government budgets, utilizing available resources is critical. The federal government, through many of its agencies, posts extreme heat event public preparedness information on a number of its websites. Just as excessive heat warnings and heat advisories issued by the NWS are used to by local governments to inform their local warning systems, the extreme heat event public preparedness information provided by federal agencies such as the National Weather Service, CDC, and Federal Emergency Management Agency (FEMA) could be used by local governments to inform the content communicated to the public to promote appropriate heat-health knowledge and preventive actions.

The public has access to the federal preparedness extreme heat event sites, but the information is dispersed across so many sites that the volume of information may overwhelm a person seeking information. Additionally, extreme heat events are experienced by the public within their local community. Certain information that the public needs to respond effectively requires specific local knowledge. For example, the public are directed to spend time in air conditioning, and local information about official cooling stations and other places where the public can get a respite from the heat, as well as transportation to those locations are locally specific information. As a local government, the websites are an opportunity to organize and convey the information to the public in a manner that is both locally relevant and effectively conveyed. The foundation for effective communication is that the 
content include relevant information on populations at risk and actions to mitigate risk.

The goal of this study was to examine the heat preparedness and response content communicated to the public on local government websites. This goal was achieved by first developing a comprehensive rubric of heat-health response strategies to excessive heat events that the public can undertake to reduce heat-health risks. The rubric was based on content from federal government agencies responsible for heat-health planning and response. Then, municipal government excessive heat event websites of the 10 most populous U.S. cities were examined. The result was the identification of heat-health content included and omitted from local government extreme heat event public preparedness websites.

\section{Methods to review federal websites and documents to create the Extreme Heat Event Public Response Rubric}

To create the Extreme Heat Event Public Response Rubric, federal government web pages and documents containing general public heat-health content were identified. The process to identify potential content to review started with a Google search using the terms "extreme heat" and "government." This yielded search results that were included if the sites were official U.S. federal government websites with landing page content that indicated a focus on extreme heat and heat-health information designed for the general public. Websites were omitted from review if they were not official federal government websites or if the initial landing page indicated a topic other than extreme heat and public heat-health information.

When a website was determined to be appropriate for inclusion, the landing page was reviewed. Then, each link on the landing page was opened and reviewed. Using the same approach, all links within the secondary pages were opened and reviewed. This process continued until the links were only linking back to previously reviewed pages, the links were no longer providing additional extreme heat information, and/or the links were to other federal agencies providing heat-health information. The landing page and all subsequent relevant links from that agency are identified as a single source.

When a link to another federal agency was identified, the process detailed above was repeated from that agency's landing page and subsequent relevant pages being reviewed as a single source. This process of using the search results from the Google search as well as embedded links to additional federal web pages and documents continued until the reviews ceased to provide additional information (i.e., information saturation was achieved) that had not already been provided in a previously reviewed website or document. This process led to the inclusion of one federal consortium (NIHHIS) and three federal agency [CDC, Department of Homeland Security (DHS), and Department of Labor (DOL)] websites. Additionally, to ensure inclusion of relevant federal agencies, a search was conducted to specifically include the Occupational Safety and Health Administration (OSHA) and National
Institutes of Health (NIH) using the same procedure for exploring their EHE websites. Finally, two federally developed "guidebooks" were identified for inclusion. These are multipage PDFs (documents) and were reviewed as separate sources. Table 1 contains a list of the federal agencies and consortia websites and the documents used to create the rubric.

The rubric was created using a structured approached referred to as direct content analysis method. Specifically, direct content analysis starts with a general understanding of the phenomena being examined, which in this case is preparedness communication and heat health and starts coding with the first read through from this frame. The frame was informed by prior research on heat health, including research that identified populations at risk for adverse health outcomes including death (see Anderson and Bell 2011; Matte et al. 2016; Semenza et al. 1996) and the public's lack of understanding of actions to take to mitigate risk (see Bassil and Cole 2010; Sheridan 2007). Therefore, direct content analysis was used to initially code within the general categories of populations, knowledge, and actions as the websites and documents were reviewed. A "Y" in Table 1 indicates that the items were found in that source.

Through repeated review and coding of the websites and documents, themes emerged within the two broad categories. The themes were then refined into the within the rubric to be populations at greater risk and actions to reduce risk. Within each broad organizational frame, content was then organized into categories that included either specific populations or action statements. The rubric was designed to be checklist so that it could be used to examine the presence of each element on the local government public preparedness extreme heat event websites.

\section{Extreme Heat Event Public Response Rubric}

The Extreme Heat Event Public Response Rubric was created based on an analysis of federal agency web pages and documents. While there is not uniform representation of each item across the sources reviewed, the rubric represents a comprehensive list of elements presented across all of the websites and documents. Additionally, the rubric applies to all locations and this approach is consistent with the federal-level presentation of heat-health information.

The first section contains a list of populations at greater risk for negative heat-health experiences due to characteristic(s) or a greater likelihood of exposure during an EHE. The second frame includes the myriad of actions to reduce heat-health risk that the public should take to reduce the likelihood of an adverse heat-heath experience. Separating out the populations at greater risk and the actions to reduce heat-health risk is important because it allows for a focus on each and clarity that the actions to reduce risk apply to the population as a whole and not just by subpopulations at greater risk. Therefore, the actions to reduce risk, in general, apply to all populations regardless of underlying vulnerability. Table 1 details 
TABLE 1. Federal sources examined and information used by source to develop the extreme heat event public response rubric; "Y" indicates that the items were found in that source.

\begin{tabular}{|c|c|c|c|c|c|c|c|c|}
\hline \multirow[b]{2}{*}{ Pages and items reviewed: } & \multicolumn{8}{|c|}{ Items included by federal website or document } \\
\hline & $1^{\mathrm{a}}$ & $2^{\mathrm{b}}$ & $3^{\mathrm{c}}$ & $4^{\mathrm{d}}$ & $5^{\mathrm{e}}$ & $6^{\mathrm{f}}$ & $7^{\mathrm{g}}$ & $8^{\mathrm{h}}$ \\
\hline $\begin{array}{l}\text { Web pages: No. of pages reviewed, including landing page/(PDF files: } \\
\text { No. of pages in document) }\end{array}$ & 13 & 4 & 5 & 7 & 1 & 9 & (20) & $(60)$ \\
\hline \multicolumn{9}{|l|}{ Populations at greater risk } \\
\hline \multicolumn{9}{|l|}{ Populations at risk due to demographics and health conditions } \\
\hline Older adults/65 yr and older & $\mathrm{Y}$ & $\mathrm{Y}$ & $\mathrm{Y}$ & & Y & $\mathrm{Y}$ & Y & $\mathrm{Y}$ \\
\hline Infants and children & $\mathrm{Y}$ & $\mathrm{Y}$ & $\mathrm{Y}$ & & & $\mathrm{Y}$ & Y & $\mathrm{Y}$ \\
\hline People with preexisting health conditions & $\mathrm{Y}$ & $\mathrm{Y}$ & $\mathrm{Y}$ & $\mathrm{Y}$ & Y & $\mathrm{Y}$ & $\mathrm{Y}$ & $\mathrm{Y}$ \\
\hline People with mobility restrictions & & $\mathrm{Y}$ & & & & & $\mathrm{Y}$ & $\mathrm{Y}$ \\
\hline People with mental impairment or illness & & & & & & $\mathrm{Y}$ & $\mathrm{Y}$ & $\mathrm{Y}$ \\
\hline People under the influence of alcohol or drugs & & & & $\mathrm{Y}$ & $\mathrm{Y}$ & & $\mathrm{Y}$ & $\mathrm{Y}$ \\
\hline People who are pregnant & & & & & & $\mathrm{Y}$ & $\mathrm{Y}$ & $\mathrm{Y}$ \\
\hline People who are overweight or obese & $\mathrm{Y}$ & $\mathrm{Y}$ & $\mathrm{Y}$ & $\mathrm{Y}$ & $\mathrm{Y}$ & $\mathrm{Y}$ & $\mathrm{Y}$ & $\mathrm{Y}$ \\
\hline \multicolumn{9}{|l|}{ Populations at risk due to socioeconomics and living conditions } \\
\hline People who are socially isolated/live alone & & & & & & $\mathrm{Y}$ & $\mathrm{Y}$ & $\mathrm{Y}$ \\
\hline People who are homeless & & & $\mathrm{Y}$ & & & & $\mathrm{Y}$ & $\mathrm{Y}$ \\
\hline People living in low-income households & $\mathrm{Y}$ & & $\mathrm{Y}$ & & & $\mathrm{Y}$ & $\mathrm{Y}$ & $\mathrm{Y}$ \\
\hline People living without AC & $\mathrm{Y}$ & & $\mathrm{Y}$ & & Y & $\mathrm{Y}$ & Y & $\mathrm{Y}$ \\
\hline \multicolumn{9}{|l|}{ Populations at risk due to work or recreational activities } \\
\hline People working outdoors & $\mathrm{Y}$ & & $\mathrm{Y}$ & $\mathrm{Y}$ & & $\mathrm{Y}$ & Y & $\mathrm{Y}$ \\
\hline Emergency responders & & & $\mathrm{Y}$ & $\mathrm{Y}$ & & $\mathrm{Y}$ & & \\
\hline People working inside without AC & & & & $\mathrm{Y}$ & & $\mathrm{Y}$ & Y & $\mathrm{Y}$ \\
\hline People training or exercising outdoors & $\mathrm{Y}$ & & $\mathrm{Y}$ & & $\mathrm{Y}$ & $\mathrm{Y}$ & $\mathrm{Y}$ & $\mathrm{Y}$ \\
\hline \multicolumn{9}{|c|}{ Actions to reduce heat-health risk } \\
\hline \multicolumn{9}{|l|}{ Actions: Staying hydrated } \\
\hline Drink plenty of fluids/water & $\mathrm{Y}$ & $\mathrm{Y}$ & $\mathrm{Y}$ & $\mathrm{Y}$ & $\mathrm{Y}$ & $\mathrm{Y}$ & Y & $\mathrm{Y}$ \\
\hline Avoid alcohol, caffeine, and/or sugary drinks & $\mathrm{Y}$ & & $\mathrm{Y}$ & & Y & $\mathrm{Y}$ & $\mathrm{Y}$ & $\mathrm{Y}$ \\
\hline $\begin{array}{l}\text { If a medical condition limits fluid intake (e.g., high blood pressure/ } \\
\text { salt-restricted diet) seek medical advice about fluid intake }\end{array}$ & $\mathrm{Y}$ & $\mathrm{Y}$ & $\mathrm{Y}$ & & $\mathrm{Y}$ & $\mathrm{Y}$ & & \\
\hline \multicolumn{9}{|l|}{ Actions: Eating } \\
\hline Eat light, cool, easily digestible meals/food & $\mathrm{Y}$ & & $\mathrm{Y}$ & & & $\mathrm{Y}$ & Y & $\mathrm{Y}$ \\
\hline \multicolumn{9}{|l|}{ Actions: Strategies for staying cool } \\
\hline Spend time in $\mathrm{AC}$ & $\mathrm{Y}$ & $\mathrm{Y}$ & $\mathrm{Y}$ & & Y & $\mathrm{Y}$ & Y & $\mathrm{Y}$ \\
\hline If no $\mathrm{AC}$, take cool showers or baths & $\mathrm{Y}$ & $\mathrm{Y}$ & $\mathrm{Y}$ & & $\mathrm{Y}$ & & Y & $\mathrm{Y}$ \\
\hline If no $\mathrm{AC}$, use stove and oven less to keep home cooler & $\mathrm{Y}$ & & & & Y & & $\mathrm{Y}$ & \\
\hline \multicolumn{9}{|l|}{ Actions: Using fans safely } \\
\hline In high temperatures, fans do not prevent heat-related illness & $\mathrm{Y}$ & $\mathrm{Y}$ & $\mathrm{Y}$ & & & & Y & $\mathrm{Y}$ \\
\hline In high temperatures, do not use fans to push hot air in room & $\mathrm{Y}$ & $\mathrm{Y}$ & $\mathrm{Y}$ & & & & Y & $\mathrm{Y}$ \\
\hline Use fans to vent hotter air out of room or to bring cooler air into room & & & $\mathrm{Y}$ & & & & & $\mathrm{Y}$ \\
\hline In hot weather, use fans in rooms with opened doors and/or windows & & & $\mathrm{Y}$ & & & & & $\mathrm{Y}$ \\
\hline \multicolumn{9}{|l|}{ Actions: Protecting skin and eyes } \\
\hline Wear lightweight, light-colored, loose-fitting clothes & $\mathrm{Y}$ & $\mathrm{Y}$ & $\mathrm{Y}$ & & Y & $\mathrm{Y}$ & Y & $\mathrm{Y}$ \\
\hline Wear wide-brimmed hat & $\mathrm{Y}$ & $\mathrm{Y}$ & $\mathrm{Y}$ & & & $\mathrm{Y}$ & & \\
\hline Wear sunglasses & & & $\mathrm{Y}$ & & & & & \\
\hline Wear and reapply sunscreen & $\mathrm{Y}$ & & $\mathrm{Y}$ & & & $\mathrm{Y}$ & & \\
\hline \multicolumn{9}{|l|}{ Actions: Working and playing outdoors } \\
\hline $\begin{array}{l}\text { Limit outdoor activity to cooler times of day (e.g., early mornings and } \\
\text { evenings) }\end{array}$ & $\mathrm{Y}$ & $\mathrm{Y}$ & $\mathrm{Y}$ & $\mathrm{Y}$ & & $\mathrm{Y}$ & Y & $\mathrm{Y}$ \\
\hline Eliminate outdoor activity when possible & & & $\mathrm{Y}$ & & $\mathrm{Y}$ & $\mathrm{Y}$ & $\mathrm{Y}$ & $\mathrm{Y}$ \\
\hline Acclimate to heat slowly & $\mathrm{Y}$ & & $\mathrm{Y}$ & $\mathrm{Y}$ & & $\mathrm{Y}$ & Y & $\mathrm{Y}$ \\
\hline Rest in shade & $\mathrm{Y}$ & $\mathrm{Y}$ & $\mathrm{Y}$ & $\mathrm{Y}$ & $\mathrm{Y}$ & $\mathrm{Y}$ & $\mathrm{Y}$ & \\
\hline Avoid strenuous activities & $\mathrm{Y}$ & $\mathrm{Y}$ & $\mathrm{Y}$ & & Y & $\mathrm{Y}$ & $\mathrm{Y}$ & $\mathrm{Y}$ \\
\hline \multicolumn{9}{|l|}{ Actions: Providing social support } \\
\hline Check on people at high risk for heat-related illness & & Y & $\mathrm{Y}$ & $\mathrm{Y}$ & & $\mathrm{Y}$ & Y & $\mathrm{Y}$ \\
\hline
\end{tabular}


TABLE 1. (Continued)

\begin{tabular}{|c|c|c|c|c|c|c|c|c|}
\hline \multirow[b]{2}{*}{ Pages and items reviewed: } & \multicolumn{8}{|c|}{ Items included by federal website or document } \\
\hline & $1^{\mathrm{a}}$ & $2^{\mathrm{b}}$ & $3^{\mathrm{c}}$ & $4^{\mathrm{d}}$ & $5^{\mathrm{e}}$ & $6^{\mathrm{f}}$ & $7^{\mathrm{g}}$ & $8^{\mathrm{h}}$ \\
\hline \multicolumn{9}{|l|}{ Actions: Seeking updates and safety information } \\
\hline Call public information phone lines [general (311/211) or event specific] & & $\mathrm{Y}$ & $\mathrm{Y}$ & & & & $\mathrm{Y}$ & $\mathrm{Y}$ \\
\hline Check local news and other media sources & $\mathrm{Y}$ & & $\mathrm{Y}$ & & $\mathrm{Y}$ & & $\mathrm{Y}$ & $\mathrm{Y}$ \\
\hline \multicolumn{9}{|l|}{ Actions: Knowing signs and symptoms of heat-related illnesses } \\
\hline Know signs and symptoms of heat-related illnesses & $\mathrm{Y}$ & $\mathrm{Y}$ & $\mathrm{Y}$ & $\mathrm{Y}$ & $\mathrm{Y}$ & Y & $\mathrm{Y}$ & $\mathrm{Y}$ \\
\hline Actions when heat-related illness is suspected & & $\mathrm{Y}$ & $\mathrm{Y}$ & $\mathrm{Y}$ & $\mathrm{Y}$ & & $\mathrm{Y}$ & $\mathrm{Y}$ \\
\hline \multicolumn{9}{|l|}{ Actions: Practicing car safety } \\
\hline Do not leave people in a parked car & $\mathrm{Y}$ & $\mathrm{Y}$ & $\mathrm{Y}$ & & & & $\mathrm{Y}$ & $\mathrm{Y}$ \\
\hline Do not leave pets in a parked car & & $\mathrm{Y}$ & $\mathrm{Y}$ & & & $\mathrm{Y}$ & $\mathrm{Y}$ & $\mathrm{Y}$ \\
\hline \multicolumn{9}{|l|}{ Actions: Protecting pets } \\
\hline Provide pets with freshwater & $\mathrm{Y}$ & & & & & & & \\
\hline Provide pets with access to shade & $\mathrm{Y}$ & & & & & & & \\
\hline
\end{tabular}

${ }^{\mathrm{a}} \mathrm{CDC}(2021)$.

${ }^{\mathrm{b}}$ DHS (2021).

${ }^{\mathrm{c}}$ NWS (2021).

${ }^{\mathrm{d}}$ DOL OSHA (2021).

e NIH NIA (2021)

${ }^{\mathrm{f}}$ NIHHIS (2021).

${ }^{\mathrm{g}} \mathrm{EPA}$ and CDC (2016).

${ }^{\mathrm{h}}$ EPA, NWS, CDC, and DHS (2016).

the elements in the checklist as well where the source of information was found in the federal websites and documents.

\section{a. Populations at greater risk}

The population characteristics determined to be at greater risk were classified into three categories in the rubric. A large number of people in any municipal area are at higher risk an adverse health experience during an extreme heat event due to a myriad of factors. This exposure to risk is compounded because many vulnerable populations lack the ability to engage effectively in preventive actions due to limitations beyond their control.

The first category identifies populations at greater risk due to demographics and health conditions. This category includes ages determined to place people at greater risk such as infants, children, and people 65 years of age or older. Health conditions that are common within the general public and that put people at heightened risk of experiencing heatrelated illnesses are also included here. Some common health conditions that can interfere with the body's ability to effectively cool itself in extreme heat referenced in the federal documents are people who are pregnant or obese. People taking medications or who have preexisting health conditions, especially those conditions that complicate maintaining hydration such as those that would require a fluid-restricted diet or mobility restrictions that would make relocating to a cooler space more difficult. Finally, the category of demographic and health conditions that place people at greater risk include conditions that may impair judgement or awareness of heat or heat-related illnesses such as alcohol and drug use.

The second category of populations at greater risk included in the rubric identifies socioeconomics and living conditions that can increase exposure to heat or reduce capacity to response effectively to reduce risk. This subgroup includes populations that experience social isolation, poverty, and homelessness. The socioeconomic conditions of these vulnerable populations limit their ability to take actions to reduce risk of an adverse health outcome during an extreme heat event. For example, people who are poor may lack the financial resources to run an air conditioning unit and may, therefore, forego that protective action. Additionally, people may not have access to air conditioning in their homes more generally, especially in more temperate climates, or may live in upper floors of building where heat will rise resulting in higher ambient room temperatures.

Finally, there is a subgroup of people exposed to extreme heat due to work or activity. This subgroup includes people who work outdoors such as construction workers, landscapers, and emergency responders. It also includes people who work indoors but without air conditioning such as people who work in automobile repair shops, garden centers, and warehouse loading docks. Additionally, this category of populations at greater risk includes athletes who train outside and people who engage in outdoor activities such as recreational runners.

\section{b. Actions to reduce risk}

The actions to reduce risk portion of the Extreme Heat Event Public Response Rubric contains 11 categories of actions that were identified in the examination of federal websites and documents. Within each category are specific actions to reduce heat-health risks during an extreme heat event. The number of categories, variety of actions, and decision-making necessary to effectively undertake the actions underscore the complexity of effective public response to an extreme heat event. 
The first two actions focus on consumption during extreme heat events. Staying hydrated was present on all of the federal websites and documents reviewed. Most include information about what to drink (i.e., cool water). Many websites and documents also included beverages to avoid such as alcoholic, sugary, and caffeinated drinks because they can contribute to dehydration. An additional action emphasizes that people with preexisting health conditions should seek medical advice on how to effectively maintain hydration during extreme heat events. Eating as an action focuses on information that meals or food should be light, cool, and easily digestible.

Strategies for staying cool are a category of actions for people to take to cool the body to reduce the risk of heat-related illnesses. Some of these strategies focus on ambient room temperatures and, specifically, keeping those temperatures at a level that reduces the risk of heat-related illnesses. First, using air conditioning is an adaptative approach to reduce indoor temperatures on hot days. People with air conditioning units are encouraged to use them. People without access to at-home air conditioning are encouraged to go to places where air condition is available such as libraries and malls for at least a few hours, especially during the hottest time of day. Additionally, to keep ambient room temperatures from rising, the public is encouraged to limit the use of stoves and ovens. In the absence of air conditioning or other means to reduce the ambient room temperature, people are advised to use approaches that facilitate the human body's natural evaporation and cooling process by taking cool baths or showers to promote cooling.

Federal websites and documents that include information on using portable fans safely address the complexity and dangers posed by their use, especially in extremely hot conditions. The use of portable fans is a complicated category within action to reduce risk. Using portable fans safely focuses on warnings about the use of fans during extreme heat events. Key to this strategy is to reduce ambient room temperature by using the fan with windows and doors open and to either point the fan outward to vent hot air from a room or point the fan inward to draw cooler air into a room. The sites also communicated that using a portable fan to push hot air around a room can increase the risk of heat-related illness by promoting perspiration evaporation and ultimately resulting in more rapid dehydration.

Protecting skin and eyes is a category in the reviewed websites and documents that provided consistent guidance that people should wear some combination of lightweight, lightcolored, and loose-fitting clothes. For skin protection, widebrimmed hats are advised, as are sunscreen and sunglasses.

Working and playing outdoors is a broad theme with general recommendations to limit or eliminate outdoor activity, as least during the hottest part of the day, in order to avoid heat-related illness. In the review of federal sources, some sources, especially those with outdoor workers and/or athletes identified as at-risk populations, recommended acclimating to the heat and avoiding strenuous activity. Additionally, taking breaks and resting in the shade is consistently communicated action.
Actions directed at information-seeking activities were present on all the federal websites and documents examined. Most often the content referred people to either a dedicated extreme heat event phoneline or, more commonly, to a general nonemergency (311) number. Additional content focused on directing the public to local news stations for more information about the extreme heat event and related response.

Providing social support focuses on actions that the public can take to reduce risks associated with isolation and to meet the needs of people who may not be able provide for themselves during high heat conditions. This category of action also emphasizes the need to "check on others" for signs and symptoms of heat-related illnesses. The providing social support category is directly but not exclusively related to the category of knowing the signs and symptoms of heat-related illnesses. All sites and documents reviewed devoted some space to presenting information on heat-related illnesses that can be conceptualized into categories of content. These are the identification of signs and symptoms of heatrelated illnesses, specific types of heat-related illnesses, and recommendations for action should heat-related illness be suspected.

The theme of practicing car safety was present in every federal source examined. The related content focuses on not leaving people or pets in parked vehicles. While this is particularly important for at-risk populations who may not be able to exit a car on their own, such as children and infants, it applies to all individuals. Related to the theme of practicing car safety is protecting pets from extreme heat. The information includes not leaving pets in a parked car and extended on some sites and documents to providing water and shade when pets are outside.

\section{Methods to examine local government extreme heat event preparedness websites}

The Extreme Heat Event Public Response Rubric was used to examine the content of the 10 most populous U.S. cities' extreme heat event preparedness websites. Three searched were conducted for each city to select the websites to be examined. The first search was conducted with a Google search using the city's name and the term "extreme heat." The second and third searches used the city's name and the terms "public health department" and "emergency management department," respectively. The inclusion criteria were that it was an official government website for the intended location and the landing page of the website had to mention extreme heat public preparedness. For all three searches, the first local government web page result was selected for analysis. The landing page was examined. If the landing page contained information about extreme heat, the examination continued. Otherwise, the website was omitted from further review. Starting with the landing page, each link was opened and the content examined and, if pertinent to extreme heat, included in the analysis. This continued until all the links had been opened and examined. In a few cities, public health was 
TABLE 2. Local government websites' landing pages that were examined in the summative content analysis.

\section{New York (City), New York}

New York City Emergency Management—Be ready: Extreme heat; https://www1.nyc.gov/site/em/ready/extreme-heat.page; accessed 30 April 2021

\section{Los Angeles, California}

City of Los Angeles Emergency Management Department_Beat the heat; https://emergency.lacity.org/resources/beat-heat; accessed 30 April 2021

Los Angeles County Chief Executive Office/Office of Emergency Management-Ready LA County: Extreme heat; https://ready. lacounty.gov/heat/; accessed 30 April 2021

County of Los Angeles Public Health_Climate change and sustainability: Extreme heat; http://www.lapublichealth.org/eh/ climatechange/ExtremeHeat.htm;accessed 30 April 2021

Chicago, Illinois

City of Chicago Emergency and Communications-Weather extremes: Extreme temperature; https://www.chicago.gov/city/en/ depts/oem/supp_info/alertrespond/extremetemps.html; accessed 1 May 2021

\section{Houston, Texas}

City of Houston, Office of Emergency Management-Be prepared: Protecting yourself during extreme heat; https://www. houstonoem.org/extreme-heat/; accessed 1 May 2021

Harris County Public Health (home $\rightarrow$ resources $\rightarrow$ preparedness: Extreme weather $\rightarrow$ Extreme heat advisory) - Beat the heat; https://publichealth.harriscountytx.gov/Portals/27/Documents/Resources/Beat\%20the\%20Heat/Beat\%20The\%20Heat_6_8_18_ English.pdf?ver=2018-06-08-171502-383; accessed 1 May 2021

Harris County Public Health (home $\rightarrow$ resources $\rightarrow$ preparedness: Extreme weather $\rightarrow$ Extreme heat advisory) —Cool tips to beat the heat; https://publichealth.harriscountytx.gov/Portals/27/Documents/Resources/Beat\%20the\%20Heat/Cool\%20Tips. pdf?ver=2018-06-08-172308-170; accessed 1 May 2021

\section{Phoenix, Arizona}

City of Phoenix —Summer heat safety; https://www.phoenix.gov/pio/summer/heat; accessed 3 May 2021 Philadelphia, Pennsylvania

City of Philadelphia-Safety and emergency preparedness; https://www.phila.gov/services/safety-emergency-preparedness/naturalhazards/excessive-heat/; accessed 3 May 2021

San Antonio, Texas

City of San Antonio San Antonio Fire Department-Extreme heat; https://www.sanantonio.gov/SAFD/Public-Education/OtherHelpful-Information/Extreme-Heat; accessed 3 May 2021

City of San Antonio Office of Emergency Management-Beat the heat; https://www.saoemprepare.com/BeInformed/ NaturalDisasters/Heat/BeatTheHeat; accessed 3 May 2021

San Diego, California

San Diego County Health and Human Services Agency-Extreme heat; https://www.sandiegocounty.gov/hhsa/programs/phs/ extreme_heat/; accessed 4 May 2021

Dallas, Texas

City of Dallas Office of Emergency Management-Extreme heat; https://dallascityhall.com/departments/ officeemergencymanagement/Pages/Extreme-Heat.aspx; accessed 5 May 2021

San Jose, California

Santa Clara County Public Health—Hot weather tips; https://publichealth.sccgov.org/health-information/emergency-preparedness/ hot-weather-tips; accessed 5 May 2021

delegated to, or partnered with, the county, and in those locations the county web pages were used. Table 2 contains a list of the website landing pages used for the analysis.

The web pages were analyzed using a summative content analysis. A summative content analysis uses a frame identified prior to engagement with the data (Hsieh and Shannon 2005), in this case the frame is the Extreme Heat Event Public Response Rubric. If the content on the web page aligned with an item in the checklist, that information was recorded as a "Y." Table 3 contains the results for each city.

\section{Results of examining local government extreme heat event preparedness websites}

All of the 10 most populous cities in the United States have identified extreme heat as a hazard and have included it in emergency and public health preparedness plans. In all locations, extreme heat events are defined consistent with the federal guidance as a weather-related event that occurs during the summer and consists of temperatures hotter and/or more humid than average, often for 2 or more consecutive days. Location-specific definitions that would trigger an extreme heat event are included in emergency plans but are often excluded from extreme heat event public preparedness websites.

Populations at greater risk was presented in a limited manner in each of the local government websites. Each city identified at least one population at elevated risk either as primary content or in conjunction with an action such as social support. The populations at greater risk subtheme of demographics and health conditions were the most common population category presented on the sites, with all including older adults, infants and children, and people with preexisting 
TABle 3. A comparison of the Extreme Heat Event Public Response Rubric and city web pages; "Y" indicates that the content on the web page aligns with an item in the rubric checklist. This table can be used to identify gaps in information coverage for a given city. The city codes in the table head are $1=$ New York, $2=$ Los Angeles, $3=$ Chicago, $4=$ Houston, $5=$ Phoenix, $6=$ Philadelphia, $7=$ San Antonio, $8=$ San Diego, $9=$ Dallas, and $10=$ San Jose.

\begin{tabular}{llllllllllll}
\hline \hline Cities: & 1 & 2 & $3^{\text {c }}$ & 4 & 5 & 6 & 7 & 8 & 9 & 10 \\
\hline
\end{tabular}

Populations at greater risk

Populations at risk because of demographics and health conditions

Older adults/65 yr and older

Infants and children

People with preexisting health conditions

People with mobility restrictions

People with mental impairment or illness

People under the influence of alcohol or drugs

People who are pregnant

People who are overweight or obese

Populations at risk because of socioeconomics and living conditions

People who are socially isolated/live alone

People who are homeless

People living in low-income households

People living without AC

Populations at risk because of work or recreational activities

People working outdoors

Emergency responders

People working inside without AC

People training or exercising outdoors

Actions: Staying hydrated

Drink plenty of fluids/water

Avoid alcohol, caffeine, and/or sugary drinks

If a medical condition limits fluid intake (e.g., high blood pressure/ salt-restricted diet) seek medical advice on fluid intake

Actions: Eating

Eat light, cool, easily digestible meals/food

Actions: Strategies for staying cool

Spend time in AC

If no $\mathrm{AC}$, take cool showers or baths

If no $\mathrm{AC}$, use stove and oven less to keep home cooler

Actions: Using fans safely

In high temperatures, fans do not prevent heat-related illness

In high temperatures, do not use fans to push hot air in room

Use fans to vent hotter air out of room or to bring cooler air into room

In hot weather, use fans in rooms with opened doors and/or windows

Actions: Protecting skin and eyes

Wear lightweight, light-colored, loose-fitting clothes

Wear wide-brimmed hat

Wear sunglasses

Wear and reapply sunscreen

Actions: Working and playing outdoors

Limit outdoor activity to cooler times of day (e.g., early mornings and evenings)

Eliminate outdoor activity when possible

Acclimate to heat slowly

Rest in shade

Avoid strenuous activities

Actions: Providing social support

Check on people at high risk for heat-related illness

Actions: Seeking updates and safety information

Call public information phone lines [general (311/211) or event specific] Check local news and other media sources

$\begin{array}{llllllllll}\mathrm{Y} & \mathrm{Y} & \mathrm{Y} & \mathrm{Y} & \mathrm{Y} & \mathrm{Y} & \mathrm{Y} & \mathrm{Y} & \mathrm{Y} & \mathrm{Y} \\ \mathrm{Y} & \mathrm{Y} & \mathrm{Y} & \mathrm{Y} & \mathrm{Y} & \mathrm{Y} & \mathrm{Y} & \mathrm{Y} & \mathrm{Y} & \mathrm{Y} \\ \mathrm{Y} & \mathrm{Y} & \mathrm{Y} & \mathrm{Y} & \mathrm{Y} & \mathrm{Y} & \mathrm{Y} & \mathrm{Y} & \mathrm{Y} & \mathrm{Y} \\ \mathrm{Y} & & & & \mathrm{Y} & & & & \mathrm{Y} & \\ \mathrm{Y} & & & \mathrm{Y} & & & & \mathrm{Y} & & \mathrm{Y} \\ \mathrm{Y} & & & & \mathrm{Y} & & & \mathrm{Y} & & \mathrm{Y} \\ \mathrm{Y} & \mathrm{Y} & \mathrm{Y} & & & \mathrm{Y} & & & & \\ \mathrm{Y} & & \mathrm{Y} & \mathrm{Y} & \mathrm{Y} & & & \mathrm{Y} & \mathrm{Y} & \end{array}$

$\begin{array}{lllllll}\mathrm{Y} & \mathrm{Y} & \mathrm{Y} & & & \mathrm{Y} \\ \mathrm{Y} & & & \mathrm{Y} & \mathrm{Y} & \mathrm{Y}\end{array}$

$\begin{array}{ccccccccc}\mathrm{Y} & \mathrm{Y} & & & & \mathrm{Y} & \mathrm{Y} & & \mathrm{Y} \\ \mathrm{Y} & \mathrm{Y} & \mathrm{Y} & \mathrm{Y} & \mathrm{Y} & \mathrm{Y} & \mathrm{Y} & \mathrm{Y} & \end{array}$

$\begin{array}{llllllll}\mathrm{Y} & \mathrm{Y} & \mathrm{Y} & \mathrm{Y} & \mathrm{Y} & \mathrm{Y} & \mathrm{Y} & \mathrm{Y}\end{array}$

$\begin{array}{llllllllll}\mathrm{Y} & \mathrm{Y} & \mathrm{Y} & \mathrm{Y} & \mathrm{Y} & \mathrm{Y} & \mathrm{Y} & \mathrm{Y} & \mathrm{Y} & \mathrm{Y} \\ & \mathrm{Y} & \mathrm{Y} & \mathrm{Y} & \mathrm{Y} & \mathrm{Y} & \mathrm{Y} & \mathrm{Y} & \mathrm{Y} & \mathrm{Y}\end{array}$

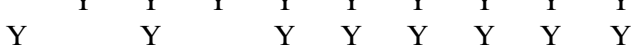

Y Y $\quad$ Y

$\begin{array}{llllllllll}Y & Y & Y & Y & Y & Y & Y & Y & Y & Y\end{array}$

$\begin{array}{llllllllll}Y & Y & Y & Y & Y & Y & Y & Y & Y & Y\end{array}$

$\mathrm{Y}$

$\begin{array}{lllllll}\mathrm{Y} & \mathrm{Y} & \mathrm{Y} & \mathrm{Y} & \mathrm{Y} & \mathrm{Y} & \mathrm{Y} \\ \mathrm{Y} & & & \mathrm{Y} & & & \mathrm{Y}\end{array}$

$\begin{array}{ll}\mathrm{Y} & \mathrm{Y} \\ \mathrm{Y} & \end{array}$

$\begin{array}{llllllllll}Y & Y & Y & Y & Y & Y & Y & Y & Y & Y\end{array}$

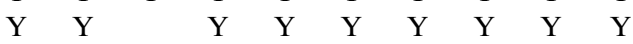

$\begin{array}{llllllllll} & & & & \mathrm{Y} & \mathrm{Y} & & & & \mathrm{Y} \\ \mathrm{Y} & \mathrm{Y} & \mathrm{Y} & \mathrm{Y} & \mathrm{Y} & \mathrm{Y} & \mathrm{Y} & \mathrm{Y} & \end{array}$

$\begin{array}{llllllllll} & & & & & & & & & \\ & Y & Y & Y & Y & Y & Y & Y & Y\end{array}$

$\begin{array}{llll} & & \\ Y & Y & Y\end{array}$

$\begin{array}{cccccccccc} & \mathrm{Y} & & & \mathrm{Y} & & \mathrm{Y} & & & \\ & & & \mathrm{Y} & & & \mathrm{Y} & & & \\ \mathrm{Y} & \mathrm{Y} & \mathrm{Y} & \mathrm{Y} & \mathrm{Y} & \mathrm{Y} & \mathrm{Y} & & \mathrm{Y} & \mathrm{Y} \\ \mathrm{Y} & \mathrm{Y} & \mathrm{Y} & & \mathrm{Y} & & & \mathrm{Y} & \mathrm{Y} & \end{array}$

$\begin{array}{llllllllll}\mathrm{Y} & \mathrm{Y} & \mathrm{Y} & \mathrm{Y} & \mathrm{Y} & \mathrm{Y} & \mathrm{Y} & \mathrm{Y} & \mathrm{Y} & \mathrm{Y}\end{array}$

$\begin{array}{llllllll}\mathrm{Y} & \mathrm{Y} & \mathrm{Y} & \mathrm{Y} & \mathrm{Y} & \mathrm{Y} & \mathrm{Y} & \mathrm{Y}\end{array}$

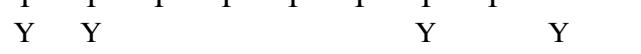


TABLE 3. (Continued)

\begin{tabular}{|c|c|c|c|c|c|c|c|c|c|c|}
\hline Cities: & 1 & 2 & $3^{\mathrm{c}}$ & 4 & 5 & 6 & 7 & 8 & 9 & 10 \\
\hline \multicolumn{11}{|c|}{ Actions: Knowing signs and symptoms of heat-related illnesses } \\
\hline Know signs and symptoms of heat-related illnesses & $\mathrm{Y}$ & $\mathrm{Y}$ & $\mathrm{Y}$ & $\mathrm{Y}$ & $\mathrm{Y}$ & $\mathrm{Y}$ & $\mathrm{Y}$ & $\mathrm{Y}$ & $\mathrm{Y}$ & \\
\hline Actions when heat-related illness is suspected & $\mathrm{Y}$ & $\mathrm{Y}$ & $\mathrm{Y}$ & $\mathrm{Y}$ & $\mathrm{Y}$ & $\mathrm{Y}$ & $\mathrm{Y}$ & $\mathrm{Y}$ & $\mathrm{Y}$ & \\
\hline \multicolumn{11}{|l|}{ Actions: Practicing car safety } \\
\hline Do not leave people in a parked car & $\mathrm{Y}$ & $\mathrm{Y}$ & $\mathrm{Y}$ & $\mathrm{Y}$ & $\mathrm{Y}$ & $\mathrm{Y}$ & $\mathrm{Y}$ & $\mathrm{Y}$ & $\mathrm{Y}$ & $\mathrm{Y}$ \\
\hline Do not leave pets in a parked car & $\mathrm{Y}$ & $\mathrm{Y}$ & $\mathrm{Y}$ & $\mathrm{Y}$ & $\mathrm{Y}$ & $\mathrm{Y}$ & $\mathrm{Y}$ & $\mathrm{Y}$ & $\mathrm{Y}$ & $\mathrm{Y}$ \\
\hline \multicolumn{11}{|l|}{ Actions: Protecting pets } \\
\hline Provide pets with fresh water & $\mathrm{Y}$ & $\mathrm{Y}$ & & $\mathrm{Y}$ & $\mathrm{Y}$ & $\mathrm{Y}$ & $\mathrm{Y}$ & $\mathrm{Y}$ & $\mathrm{Y}$ & $\mathrm{Y}$ \\
\hline Provide pets with access to shade & $\mathrm{Y}$ & $\mathrm{Y}$ & & $\mathrm{Y}$ & $\mathrm{Y}$ & $\mathrm{Y}$ & $\mathrm{Y}$ & $\mathrm{Y}$ & $\mathrm{Y}$ & $\mathrm{Y}$ \\
\hline
\end{tabular}

health conditions. The remaining four categories are included with less frequency. For example, people who are pregnant are mentioned by only four cities. For these less frequently mentioned categories of populations at greater risk, their inclusion as an at-risk group had to be inferred through the action components on the websites. The subtheme categories of socioeconomic and living conditions were less frequently included on the local government websites with half or fewer of the locations mentioning these populations as being a greater risk. Within the subtheme of populations are greater risk due to work and recreational activities emergency responders and people working inside without air conditioning (AC) were omitted. It may be that there was an expectation that emergency responders would be included in the category of outdoor workers. Both outdoor workers and people who train or exercise outdoors were mentioned in eight of the 10 cities.

All 10 cities presented at least one category from the themes of staying hydrated, staying cool, protecting skin and eyes, providing social support, and practicing car safety on their websites. Drinking plenty of fluids/water was included by city and avoiding alcohol, caffeinated, and/or sugary beverages and seeking medical advice if on a fluid restricted diet was mentioned in almost all locations. Two cities did not direct people with fluid restrictions or other health conditions to seek medical advice to learn how to stay hydrated safely. Within the theme of staying cool, there is consistent inclusion of messaging for the public spend time in air-conditioned spaces and to take cool showers or baths.

The messaging content about protecting skin and eyes focused on wearing lightweight, light-colored, and loose-fitting clothes. The wearing of wide-brimmed hats and the use of sunscreen was mentioned in websites for nine of the cities. Three cities mentioned the use of sunglasses as a protective action. Car safety was ubiquitous, with admonishments, sometimes repeatedly, to never leave a person, especially, infants, children, older adults, people unable to exit the car, and pets in a parked car for any amount of time.

Key areas of information were less consistently presented on the local government websites. Information about the safe use of fans was often limited to statements about fans not being effective in reducing heat-related illnesses. Information on how to use the fans safely was not found on the local government websites, even in cities with portable fan distribution campaigns and low rates of at-home air conditioning availability. Additionally, information seeking most often referred people to information phone lines but did not refer people to media sources such as the local news stations where information on heat health is often communicated during the weather forecast.

In total, while the 10 most populous cities in the United States recognized extreme heat as a hazard and had web pages dedicated to public preparedness for extreme heat events, no city included all of the information in the Extreme Heat Event Public Response Rubric. The absence of key information is consistent within the populations at greater risk where many group are not presented as at risk. Given the ubiquity of every population group listed under populations at greater risk, this is not due to lack of the population's presence in the city. Likewise, many actions are not presented on most of the cities' web pages. Often, actions that are the easiest to communicate (e.g., do not leave people and pets in a parked car) that are present. Actions that are more difficult to communicate or appear to be counterintuitive (e.g., safe portable fan use) are omitted.

\section{Discussion}

Bernard and McGeehin (2004) found that more than half of the 18 cities they examined had heat wave response plans that were either nonexistent or cursory in the summer of 2002. In the almost two decades since that study, extreme heat has become recognized as a hazard and included in local emergency plans. Yet, a survey of county-level emergency and health department leaders found they were underprepared for the 2011 summer EHEs (White-Newsome et al. 2014). Further, the general public lacks an understanding of actions to take during an EHE to mitigate their risk (Weinberger et al. 2018).

Extreme heat events are complex hazards to communicate to the public. This study contributes to the literature on EHE public preparedness through the development of the Extreme Heat Event Public Response Rubric. This rubric is designed to be used by local government to access the information included in their EHE public preparedness websites.

As a demonstration of the application of this rubric, it was applied to the 10 most populous cities in the U.S.'s EHE websites. The results suggest that the rubric is a useful tool in 
analyzing the information content included in the local government websites. Local government websites provide information that is factually consistent with federal websites. Sometimes this alignment is apparent because there is a link from the city website directly to a federal website and in other cases it is evident because the exact wording from the federal website is used on the local website.

The rubric was useful in identifying gaps in local government information. Local government websites were less comprehensive in the content conveyed than is the rubric. This is evident across the themes and subthemes. For example, the theme populations at greater risk is presented selectively at the local level, and each city website omitted key at-risk segments of their population. This is not an issue of the absence of a particular population in a city because the at-risk populations identified on the federal sites are found in all cities. Rather, it is a more selective presentation of at-risk groups that could, potentially, leave some people unknowingly atrisk and could prevent organizational response to address the needs of omitted populations.

Second, there are themes that are reinforced consistently in local websites. Specifically, practicing car safety for humans and pets is found across all local websites. Likewise, subthemes of staying hydrated, staying cool, protecting skin and eyes, providing social support, and knowing the signs and symptoms of heat-related illness are present and reinforced on the local websites. This information is relatively simple, direct, and requires action that is likely to be communicated effectively to the general public with a simple image or brief wording.

More complicated content was often omitted from many of the local government EHE websites. A key example of this is found in the themes using fans safely. The action necessary to promote public safety is complex, has multiple decisions points or judgements, and may require a counterintuitive change in a person's behavior. The lack of information about these area has the potential to increase risk among the public during an EHE.

There are limitations to this study. First, the rubric was designed to be applicable across locations in the United States. EHEs are local events, and this rubric would need to be used in conjunction with locally specific information relevant to public preparedness and response. Second, the study was limited to the 10 most populous cities within the United States. These larger cities may have more resources to put into their web presence and, therefore, may be more developed than less populous cities. Alternatively, these larger cities have more complex structures. EHE website information was found in a variety of departments. It may be that more city departments may result in information being omitted because it is assumed it will be included in another department's web page. In any case, future studies need to examine EHE plans and preparedness in a variety of locations and not be limited to only cities included in the current study.

In sum, federal government, especially the CDC, Environmental Protection Agency (EPA), and NWS provide detailed EHE public preparedness guidance, but the information is spread across a number of websites and pages. The Extreme
Heat Event Public Response Rubric provides a checklist that can be used to determine information gaps in local government EHE public preparedness websites. When used to examine the local government websites, it was a useful tool. There are areas in need of improvement in the communication of extreme heat events to the public. At the local level, there is a need for clear and direct information on what constitutes a heat emergency for a specific location. Additionally, the public needs to understand what actions to take and when to take them. Future research in this area needs to focus on the public's understanding of extreme heat including effective communication and adaptive actions to reduce risk as well consider the relationship between a city's extreme heat event public preparedness communication, including website communication, and rates of heat-related morbidity and mortality.

Acknowledgments. The authors thank Dr. Anne Ettinger for commenting on an early draft of this study. The authors did not receive funding to support this research. The authors have no conflict of interest to report.

Data availability statement. The websites and documents used in this study are openly available online, as documented in the tables and references provided. The data are available from author Lisa K. Zottarelli (lzottare@utk.edu) at the University of Tennessee.

\section{REFERENCES}

Anderson, G. B., and M. L. Bell, 2011: Heat waves in the United States: Mortality risk during heat waves and effect modification by heat wave characteristics in 43 U.S. communities. Environ. Health Perspect., 119, 210-218, https://doi.org/10. 1289/ehp.1002313.

Bannister, F., and R. Connolly, 2011: The trouble with transparency: A critical review of openness in e-government. Policy Internet, 3, 1-30, https://doi.org/10.2202/1944-2866.1076.

Bassil, K. L., and D. C. Cole, 2010: Effectiveness of public health interventions in reducing morbidity and mortality during heat episodes: A structured review. Int. J. Environ. Res. Public Health, 7, 991-1001, https://doi.org/10.3390/ijerph7030991.

Bernard, S. M., and M. A. McGeehin, 2004: Municipal heat wave response plans. Amer. J. Public Health, 94, 1520-1522, https:// doi.org/10.2105/AJPH.94.9.1520.

CDC, 2019a: Mission, role and pledge. CDC, accessed 23 February 2020, https://www.cdc.gov/about/organization/mission.htm.

— 2019b: Climate-ready states and cities initiative. CDC Climate and Health, accessed 26 February 2020, https:/www. cdc.gov/climateandhealth/climate_ready.htm.

—, 2021: Natural disasters and severe weather-Extreme heat (website landing page). Department of Health and Human Services CDC, accessed 10 April 2021, https://www.cdc.gov/ disasters/extremeheat/index.html.

DeYoung, S. E., T. Wachtendorf, A. K. Farmer, and S. C. Penta, 2016: NOAA radios and neighbourhood networks: Demographic factors for channel preference for hurricane evacuation information. J. Contingencies Crisis Manage., 24, 275-285, https://doi.org/10.1111/1468-5973.12123. 
DHS, 2021: Ready_Extreme heat (website landing page). DHS, accessed 11 April 2021, https://www.ready.gov/heat.

Diwanji, V. S., L. Arpan, M. B. Ulak, J. Hou, E. E. Ozguven, and R. Arghandeh, 2020: Understanding citizens' communication channel preferences during natural disasters: A synchronicitybased, mixed-methods exploration using survey and geospatial analysis. Int. J. Disaster Risk Reduct., 47, 101646, https:// doi.org/10.1016/j.ijdrr.2020.101646.

DOL OSHA, 2021: Heat illness prevention campaign-Water. Rest. Shade. Keeping workers safe in the heat (website landing page). DOL OSHA, accessed 14 April 2021, https://www. osha.gov/heat.

Ebbers, W., M. Jansen, and A. van Deursen, 2016: Impact of the digital divide on e-government: Expanding from channel choice to channel usage. Gov. Inf. Quart., 33, 685-692, https://doi.org/10.1016/j.giq.2016.08.007.

EPA and CDC, 2016: Climate change and extreme heat: What you can do to prepare. EPA and CDC Rep. EPA 430-R-16061, 20 pp., https://www.epa.gov/sites/production/files/2016-10/ documents/extreme-heat-guidebook.pdf.

- NWS, CDC, and DHS, 2016: Extreme heat events guidebook. EPA, NOAA/NWS, CDC, and DHS/FEMA Rep. EPA 430-B-16-001 and updated appendix A, 60 pp., https:// www.epa.gov/sites/production/files/2016-03/documents/eheguide_ final.pdf.

Friedman, D. B., M. Tanwar, and J. V. Richter, 2008: Evaluation of online disaster and emergency preparedness resources. Prehosp. Disaster Med., 23, 438-446, https://doi.org/10.1017/ S1049023X00006178.

Fuhrmann, C. M., M. M. Sugg, C. E. Konrad, and A. Waller, 2016: Impact of extreme heat events on emergency department visits in North Carolina (2007-2011). J. Commun. Health, 41, 146-156, https://doi.org/10.1007/s10900-015-0080-7.

Hawkins, M. D., V. Brown, and J. Ferrell, 2017: Assessment of NOAA National Weather Service methods to warn for extreme heat events. Wea. Climate Soc., 9, 5-13, https://doi. org/10.1175/WCAS-D-15-0037.1.

Henderson, H. C., J. Hong, D. B. Friedman, D. E. Porter, A. C. Halfacre, G. I. Scott, and J. R. Lead, 2016: A content analysis of internet resources about the risks of seafood consumption. Int. J. Environ. Health Res., 26, 433-447, https://doi.org/10. 1080/09603123.2015.1135313.

Hsieh, H. F., and S. E. Shannon, 2005: Three approaches to qualitative content analysis. Qual. Health Res., 15, 1277-1288, https://doi.org/10.1177/1049732305276687.

Liu, B. F., J. D. Fraustino, and Y. Jin, 2016: Social media use during disasters: How information form and source influence intended behavioral responses. Commun. Res., 43, 626-646, https://doi.org/10.1177/0093650214565917.

Madrigano, J., K. Lane, N. Petrovic, M. Ahmed, M. Blum, and T. Matte, 2018: Awareness, risk perception, and protective behaviors for extreme heat and climate change in New York City. Int. J. Environ. Res. Public Health, 15, 1433, https://doi. org/10.3390/ijerph15071433.

Matte, T. D., K. Lane, and K. Ito, 2016: Excess mortality attributable to extreme heat in New York City, 1997-2013. Health Secur., 14, 64-70, https://doi.org/10.1089/hs.2015.0059.

McDonough, B., E. Felter, A. Downes, and J. Trauth, 2015: Communicating public health preparedness information to pregnant and postpartum women: An assessment of Centers for Disease Control and Prevention web pages. Disaster Med. Public Health Prep., 9, 134-137, https://doi.org/10.1017/dmp. 2015.2.
NIH NIA, 2021: Hot weather safety for older adults (website landing page). NIH National Institute on Aging (NIA), accessed 15 April 2021, https://www.nia.nih.gov/health/hotweather-safety-older-adults.

NIHHIS, 2020: About NIHHIS. NOAA, accessed 2 December 2020, https://nihhis.cpo.noaa.gov/About-NIHHIS.

- 2021: NIHHIS home page (website landing page). NOAA, accessed 18 April 2021, https://nihhis.cpo.noaa.gov/.

NWS, 2020: The National Weather Service (NWS): About the NWS. NOAA, accessed 26 February 2020, https://www. weather.gov/about/.

_ 2021: Heat safety tips and resources (website landing page). Department of Commerce/NOAA/NWS, accessed 12 April 2021, https://www.weather.gov/safety/heat.

Reddick, C., and L. Anthopoulos, 2014: Interactions with e-government, new digital media, and traditional channel choices: Citizen-initiated factors. Transforming Gov., 8, 398-419, https://doi.org/10.1108/TG-01-2014-0001.

Schmalzried, H., L. Fleming Fallon, and E. Harper, 2012: Assessing informational website communications during emergencies and disasters. J. Philanthropy Mark., 17, 199-207, https:// doi.org/10.1002/nvsm.1423.

Semenza, J. C., C. H. Rubin, K. H. Falter, J. D. Selanikio, W. D. Flanders, H. L. Howe, and J. L. Wilhelm, 1996: Heat-related deaths during the July 1995 heat wave in Chicago. N. Engl. J. Med., 335, 84-90, https://doi.org/10. 1056/NEJM199607113350203.

Sheridan, S. C., 2007: A survey of public perceptions and response to heat warnings across four North American cities: An evaluation of municipal effectiveness. Int. J. Biometeor., 52, 3-15, https://doi.org/10.1007/s00484-006-0052-9.

Union of Concerned Scientists, 2019: Extreme heat \& climate change: How often will you endure extreme heat where you live? Accessed 19 October 2019, https://www.ucsusa.org/ resources/killer-heat-interactive-tool?location $=$ new-yorkcounty-ny.

Weinberger, K. R., A. Zanobetti, J. Schwartz, and G. A. Wellenius, 2018: Effectiveness of National Weather Service heat alerts in preventing mortality in 20 US cities. Environ. Int., 116, 30-38, https://doi.org/10.1016/j.envint.2018.03.028.

Weisskopf, M. G., H. A. Anderson, S. Foldy, L. P. Hanrahan, K. Blair, T. J. Török, and P. D. Rumm, 2002: Heat wave morbidity and mortality, Milwaukee, Wis, 1999 vs 1995: An improved response? Amer. J. Public Health, 92, 830-833, https://doi.org/10.2105/AJPH.92.5.830.

White-Newsome, J. L., B. Ekwurzel, M. Baer-Schultz, K. L. Ebi, M. S. O'Neill, and G. B. Anderson, 2014: Survey of countylevel heat preparedness and response to the 2011 summer heat in 30 U.S. states. Environ. Health Perspect., 122, 573579, https://doi.org/10.1289/ehp.1306693.

Wimble, M., 2016: Understanding health and health-related behavior of users of internet health information. Telemed. e-Health, 22, 809-815, https://doi.org/10.1089/tmj. 2015.0267.

Zhang, K., T. H. Chen, and C. Begley, 2015: Impact of the 2011 heat wave on mortality and emergency department visits in Houston, Texas. Environ. Health, 14, 11, https://doi.org/10. 1186/1476-069X-14-11.

Zottarelli, L. K., H. O. Sharif, X. Xu, and T. S. Sunil, 2020: Effects of social vulnerability and heat index on emergency medical service incidents in San Antonio, Texas, in 2018. J. Epidemiol. Commun. Health, 75, 271-276, https://doi.org/10.1136/ jech-2019-213256. 